\title{
Evaluation of Insulin Sensitivity in Obese Offspring of Diabetic Rats by Hyperinsulinemic- Euglycemic Clamp Technique
}

\author{
NANCY L. GELARDI, CHUNG-JA M. CHA, AND WILLIAM OH \\ Brown University Program in Medicine, Department of Pediatrics, Women and Infants Hospital of Rhode Island, \\ Providence, Rhode Island 02905
}

\begin{abstract}
Young adult macrosomic offspring of streptozotocin-induced mildly hyperglycemic rats exhibit accelerated growth through the first 10 wk of age. At 10 wk, oral glucose loading resulted in elevated plasma insulin and glucose concentrations compared to controls. To assess the mechanism of the abnormal glucose tolerance in vivo, hyperinsulinemic-euglycemic clamp studies were performed. Ten-wk-old rats were fasted overnight, and porcine insulin was infused $\left(2.4 \mathrm{mU} \cdot \mathrm{kg}^{-1} \cdot \mathrm{min}^{-1}\right)$. Glucose was infused concurrently at varying rates to maintain euglycemia for 40-60 min. Insulin levels were raised from a baseline value of $163 \pm 57 \mathrm{pmol} / \mathrm{L}(23 \pm 8 \mu \mathrm{U} / \mathrm{mL})(\mathrm{SD})$ to $476 \pm 57 \mathrm{pmol} / \mathrm{L}(67 \pm 8 \mu \mathrm{U} / \mathrm{mL})$ at steady state for males and from $178 \pm 43 \mathrm{pmol} / \mathrm{L}(25 \pm 6 \mu \mathrm{U} / \mathrm{mL})$ to 454 $\pm 43 \mathrm{pmol} / \mathrm{L}(64 \pm 6 \mu \mathrm{U} / \mathrm{mL})$ for females. The results showed that the macrosomic male and female animals were significantly less sensitive to the effects of insulin than were their respective controls; this was evident by a lower increment in glucose disposal rate per unit increase in insulin $(0.04 \pm 0.01$ versus $0.11 \pm 0.03$ for males and 0.05 \pm 0.03 versus $0.18 \pm 0.07 \mathrm{mg} \cdot \mathrm{kg}^{-1}$ per $\mu \mathrm{U} / \mathrm{mL}$ for females). The endogenous glucose production by the liver in the basal (fasted) state in the macrosomic group compared to controls was higher, suggesting possible hepatic insulin resistance. However, endogenous glucose production was suppressed to the same degree between the experimental and control groups during the hyperinsulinemic period, suggesting that the hepatic insulin resistance can be overcome by high insulin levels. Thus, the reduced sensitivity to the effect of insulin on glucose disposal in the macrosomic animals provides additional in vivo evidence for peripheral insulin resistance as a contributing factor for the development of glucose intolerance in obese offspring of mildly hyperglycemic dams. (Pediatr Res 30: 40-44, 1991)
\end{abstract}

Abbreviations

STZ, streptozotocin

Vohr et al. (1) have observed that infants of mothers with poorly controlled diabetes mellitus are at risk for neonatal macrosomia. In addition, these infants have been shown to be predisposed to the development of obesity in adolescence (2).

Received July 27, 1990; accepted February 25, 1991.

Correspondence and reprint requests: William Oh, M.D., Department of Pediatrics, Women \& Infants Hospital, 101 Dudley Street, Providence, RI 02905.

Supported by the Perinatal Emphasis Research Center HD 11343-10 funded by National Institute of Child Health and Human Development, Bethesda, MD.
Adolescent obesity has been associated with the development of diabetes mellitus in adulthood (3).

Using an animal model to explore the association between increased birth weight and the predisposition of these infants to the development of adult onset diabetes, we have observed that the obese rat pups of mildly hyperglycemic dams maintain accelerated body weight gain and develop glucose intolerance by $12 \mathrm{wk}$ of age (4). To further examine the mechanism of the abnormal glucose metabolism, we studied insulin receptor characteristics and insulin-stimulated glucose utilization of adipocytes of 10 -wk-old obese and control rats (5). The obese rats, both male and female, showed reduced insulin-stimulated glucose utilization as well as a lower receptor capacity compared to control animals. These data were interpreted to suggest that the observed defect in glucose metabolism was associated with a blunted insulin response in the adipocyte that is probably postreceptor in nature. To determine whether the insulin resistance observed in vitro in adipose tissue has any in vivo counterpart and whether the livers of these obese offspring of hyperglycemic dams display any insulin resistance, the euglycemic-hyperinsulinemic clamp technique was employed.

The euglycemic-hyperinsulinemic clamp technique has been used to study glucose metabolism in the awake rat (6). The euglycemic insulin clamp offers advantages over previously used techniques for assessing insulin sensitivity: first, by maintaining basal glucose concentrations after insulin administration, the complex neuroendocrine responses to hypoglycemia are avoided; second, because basal glucose levels are maintained, the amount of exogenous glucose infused must equal the amount of glucose metabolized by all tissues; third, because all groups are raised to the same level of hyperinsulinemia, the insulin delivery to all experimental groups is the same; and fourth, by combining the clamp with the isotope dilution technique, endogenous glucose production can be quantified and the contributions of changes in hepatic glucose production versus altered peripheral sensitivity to insulin can be evaluated (7).

Using the animal model that we have previously established (4) and the euglycemic-hyperinsulinemic clamp technique, we tested the hypothesis that the abnormal glucose metabolism among the obese offspring of mildly hyperglycemic mothers is a result of hepatic and peripheral tissue insulin insensitivity.

\section{MATERIALS AND METHODS}

Twelve pregnant Sprague-Dawley rats purchased from Taconic Farm (Germantown, NY) were made mildly hyperglycemic by intraperitoneal injection of STZ ( $37 \mathrm{mg} / \mathrm{kg}$ body weight) in 0.1

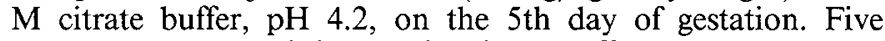
pregnant dams were injected with citrate buffer alone as a control group. The rats were housed individually in wood-chip-bedded plastic cages at $23^{\circ} \mathrm{C}$ with 12 -h light-dark cycles. All animals had free access to commercial rat chow (Purina formula 5001, Ral- 
ston Purina, St. Louis, MO). Maternal weights and blood samples (taken by cutting off the tip of the tail and gently squeezing to get blood) were obtained on d 13,16, 18, 19, and 20 of gestation. Plasma glucose concentration was measured by the glucose oxidase method on a YSI 23A Glucose Analyzer (Yellow Springs Instrument Co., Yellow Springs, $\mathrm{OH}$ ). Mild maternal diabetes was classified as plasma glucose values of between 5.55 and 16.65 $\mathrm{mmol} / \mathrm{L}$ for 4 of the $5 \mathrm{~d}$ when measurements were made. Four of the dams injected with STZ had plasma glucose values below $5.55 \mathrm{mmol} / \mathrm{L}$ and were excluded from the study. A total of 80 pups from the remaining eight STZ-treated dams and 49 pups from the five control dams were delivered spontaneously and weighed within $12 \mathrm{~h}$. Pups from the STZ-injected dams whose birth weights were greater than $2 \mathrm{SD}$ of the mean birth weight of the pups from the control dams were classified as macrosomic and included in the study. In the current study, the mean birth weight of the control pups (pups born to buffer-treated dams) was $6.25 \pm 0.44 \mathrm{~g}$. Therefore, experimental pups with birth weights greater than $7.13 \mathrm{~g}$ were included in the study. The success rate of obtaining macrosomic pups was $45 \%$ (36 of 80 pups). The nonmacrosomic pups born to STZ-treated dams had growth rates and glucose tolerance tests similar to the buffertreated control pups; thus, we used the latter as the control group.

Postnatal growth of the macrosomic and control pups was monitored by weekly weight measurements through 10 wk of age. At $10 \mathrm{wk}$, oral glucose tolerance tests were performed without anesthesia after a 15 -h fast. Basal fasting blood samples were obtained by cutting the tips of the tails as previously described. A glucose solution of $5.55 \mathrm{mmol} / \mathrm{L}$ in a $3-\mathrm{g} / \mathrm{kg}$ body weight dose was given orally via a catheter attached to a syringe. Blood samples were collected at $0.5,1.0,2.0$, and $3.5 \mathrm{~h}$ after glucose loading.

Two to $3 \mathrm{~d}$ after the oral glucose tolerance test, rats were anesthetized using ketamine, and the right external jugular veins were catheterized using polyurethane catheters. All catheters were exteriorized at the back of the neck and secured with Tether Anchoring Skin Buttons (Harvard Apparatus, South Natick, MA). Animals were allowed 2 to $3 \mathrm{~d}$ to recover from surgery, during which time the catheters were flushed once a day with heparinized saline.

Figure 1 shows the study design for the hyperinsulinemiceuglycemic clamp study. Rats were fasted for $15 \mathrm{~h}$ before the start of the clamp study. Animals were given an initial $2.22 \times$ $10^{5} \mathrm{~Bq}$ bolus of $6-{ }^{-14} \mathrm{C}$-labeled glucose $\left(0.17-0.20 \times 10^{10} \mathrm{~Bq} /\right.$ mmol; New England Nuclear, Boston, MA) via the jugular catheter. Fifteen min after the glucose bolus, baseline blood samples for glucose, insulin and ${ }^{14} \mathrm{C} \mathrm{sp}$ act were obtained from the tail vein. To avoid excess blood volume depletion, whole blood was used for glucose determination during the study. Venous hematocrits obtained at the beginning and end of each study were not significantly different $(39 \pm 2$ and $37 \pm 3$, respectively). Ten min after baseline sampling, a continuous insulin infusion (porcine insulin in 5\% BSA) was begun at a rate

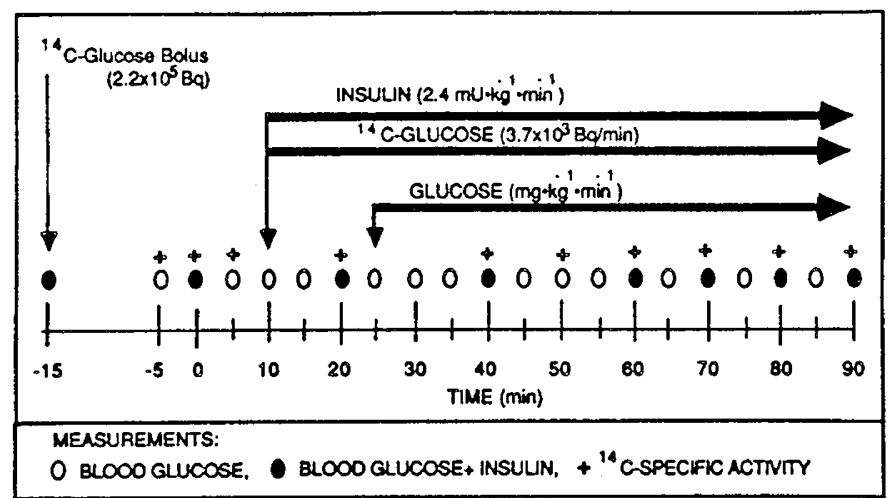

Fig. 1. Study design for hyperinsulinemic-euglycemic clamp study. of $2.4 \mathrm{mU} \cdot \mathrm{kg}^{-1} \cdot \mathrm{min}^{-1}$ using a Harvard 975 infusion pump (Harvard Apparatus Co., Inc., Millis, MA). In the same syringe, $6-{ }^{14} \mathrm{C}$-glucose was added to give a continuous infusion rate of $3.70 \times 10^{3} \mathrm{~Bq} / \mathrm{min}$. After $15 \mathrm{~min}$ of insulin administration, an infusion of a $5.55 \mathrm{mmol} / \mathrm{L}$ glucose solution was begun. Blood samples were drawn every $5 \mathrm{~min}$ to monitor glucose concentrations, and the glucose infusion rate was adjusted empirically to maintain euglycemia. Pump calibration was checked at the beginning and end of each study and was demonstrated to be accurate within $4 \pm 1 \%$ of the calibrated infusion rate. Whole blood glucose concentrations were measured on the YSI Glucose Analyzer and then corrected to the equivalent plasma glucose concentrations. The plasma insulin samples were frozen at $-80^{\circ} \mathrm{C}$ and later analyzed by RIA kit (Amersham Corp., Arlington Heights, IL) using rat insulin standards. Sp act was measured in a Mark V scintillation counter (TM Analytic, Elk Grove Village, IL). After $90 \mathrm{~min}$ of infusion, the studies were terminated and the animals killed by i.v. injection of ketamine. The calculation used to derive glucose produced was as follows:

$$
\mathrm{R}_{\mathrm{A}}=\frac{\mathrm{R}_{\mathrm{I}}}{\mathrm{Wt} \times\left(\mathrm{G}^{*} / \mathrm{G}\right)}
$$

The equation assumes that the rate of appearance $\left(R_{A}\right)$ is equal to the rate of infusion $\left(R_{I}\right)$ in cpm divided by the weight of the animal (Wt) in $\mathrm{kg}$ times the sp act of plasma glucose $\left(\mathrm{G}^{*} / \mathrm{G}\right)$ in $\mathrm{cpm}$ per mg glucose (7). Because we used whole blood, an additional factor was added to the equation to correct to plasma glucose. Within $15 \mathrm{~min}$ of the start of the labeled glucose infusion, a steady state of glucose sp act was achieved and was used to calculate glucose production in the basal state. A new steady state of glucose sp act was generally achieved by $30 \mathrm{~min}$ of the clamp study. This new plateau of sp act was then used to calculate the total rate of glucose appearance during the final $60 \mathrm{~min}$ of the clamp. The difference between the rate of glucose appearance and the exogenous glucose infusion rate represents the endogenous glucose production. Negative numbers for glucose production were interpreted as complete suppression of $R_{A}$

\section{RESULTS}

As shown in Figure 2 the plasma glucose values of the STZ treated dams were significantly higher than those of the buffertreated dams during the last $8 \mathrm{~d}$ of gestation, thereby verifying maternal hyperglycemia. Figure 3 shows the body weight changes of the pups through the first $10 \mathrm{wk}$ of age. The weights of both male and female macrosomic rats were higher than control males and females throughout the study period. The results of the oral

\section{PLASMA GLUCOSE \\ $(\mathrm{mmol} / \mathrm{L})$}

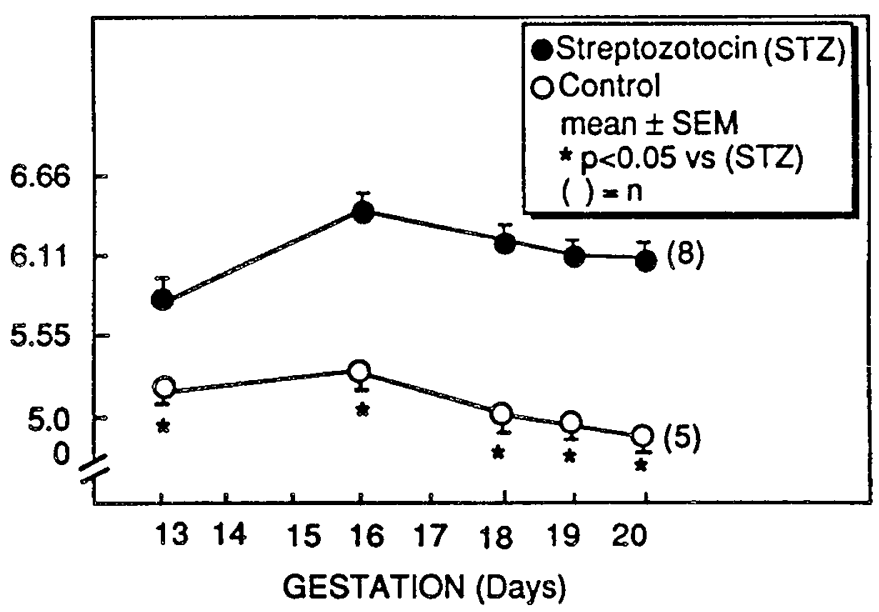

Fig. 2. Maternal glucose data during the last $8 \mathrm{~d}$ of gestation. 


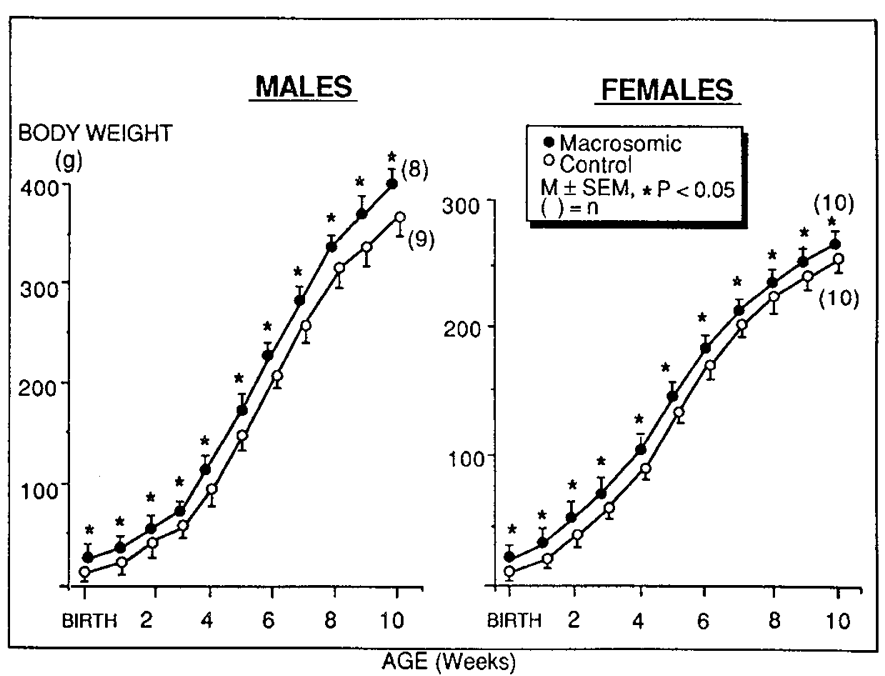

Fig. 3. Changes in body weight of the male and female rats through the first $10 \mathrm{wk}$ of age.

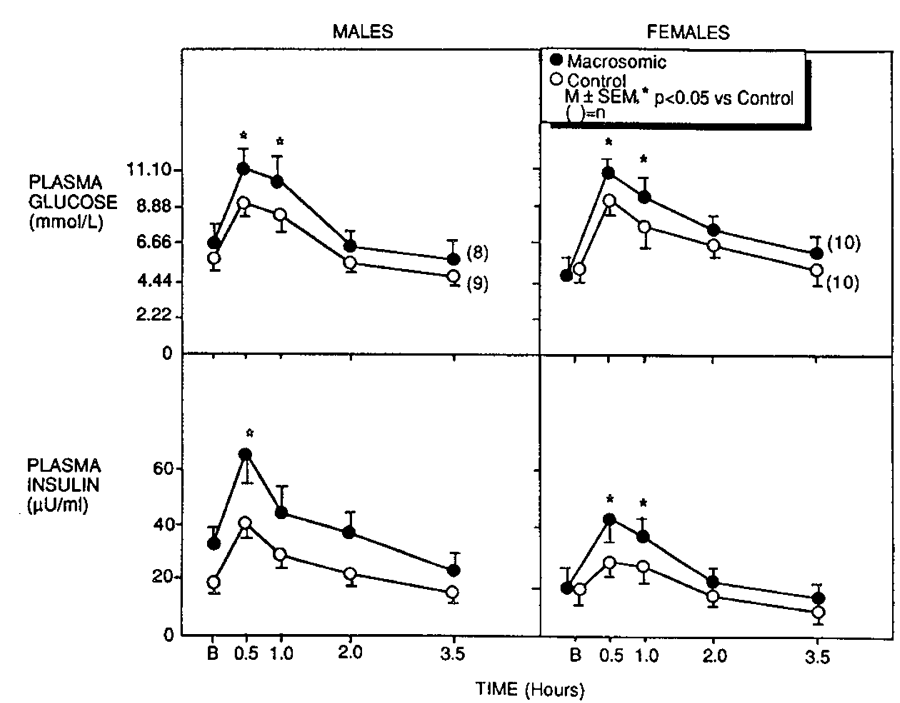

Fig. 4. Oral glucose tolerance curves in male and female rats at 10 wk of age. Three $\mathrm{g} / \mathrm{kg}$ body weight of glucose was given orally immediately after blood sampling for 15 -h fasting baseline $(B)$ values.

glucose tolerance tests are shown in Figure 4. Male macrosomic rats had elevated glucose levels at 0.5 and $1.0 \mathrm{~h}$ and elevated plasma insulin at $0.5 \mathrm{~h}$, compared to control males, after glucose loading. Similarly, female macrosomic rats showed abnormally high glucose and insulin levels at 0.5 and $1.0 \mathrm{~h}$ versus control females.

The mean body weight, basal and steady state whole blood glucose, plasma insulin values, and increment in glucose disposal rate as a measure of insulin effect of the four groups studied are shown in Table 1. At the time of study, macrosomic males and females were significantly heavier than control males and females, respectively. No differences were seen in the basal whole blood glucose or plasma insulin values among the four groups. Baseline glucose levels were maintained throughout the steady state period. Also, all groups attained and were maintained at a similar level of hyperinsulinemia during the clamp. The increment in glucose disposal (which is equal to the $R_{A}$ at steady state) divided by the increment in insulin concentration was used as a measure of insulin's effect. Control males had a significantly higher rate of glucose disposal compared to macrosomic males $\left(0.11 \pm 0.03\right.$ versus $0.04 \pm 0.01 \mathrm{mg} \cdot \mathrm{kg}^{-1} \cdot \mathrm{min}^{-1}$ per $\mu \mathrm{U} / \mathrm{mL}, p$ $<0.01)$. Similarly, control females were higher than macrosomic females $\left(0.18 \pm 0.07\right.$ versus $0.05 \pm 0.03 \mathrm{mg} \cdot \mathrm{kg}^{-1} \cdot \mathrm{min}^{-1}$ per $\mu \mathrm{U} /$
$\mathrm{mL}, p<0.001)$. Figure 5 shows the changes in whole blood glucose, plasma insulin, and amount of glucose infused during the entire clamp study of the four groups. The coefficient of variation of blood glucose during the clamp study was used as an indicator of the steady state and the effectiveness of the glucose clamp. In our study, the mean coefficient of variation at 5 -min intervals was $4.82 \pm 1.28 \%$ for control males, $3.44 \pm 1.30 \%$ for experimental males, $2.61 \pm 0.78 \%$ for control females, and 2.45 $\pm 0.58 \%$ for experimental females. Furthermore, the data in Figure 5 also show that the whole blood glucose in the macrosomic male rats was higher than that in the control males, but the differences were not statistically significant. The glucose infusion rate, however, was progressively higher in control males and females and progressively lower in macrosomic male and female rats during the course of the clamp study $(p<0.05$ by two-way analysis of variance). Table 2 shows the endogenous glucose production rates at baseline and during the steady state hyperinsulinemic period of the clamp. Basal endogenous glucose production rates were significantly higher in macrosomic male and female rats when compared with controls. These rates were all suppressed significantly during hyperinsulinemic-euglycemic states in all four groups; however, in the control males the endogenous glucose production rate was suppressed to a greater degree than in the macrosomic males $(p<0.05)$. A similar pattern was seen in the females. Net suppression of endogenous glucose production was calculated to take into account the higher basal endogenous glucose production rate of the macrosomic rats (Table 2). On an absolute body weight basis, endogenous production was suppressed to the same degree in control and macrosomic males $\left(2.23 \pm 0.21\right.$ versus $2.32 \pm 0.35 \mathrm{mg} \cdot \mathrm{kg}^{-1}$. $\mathrm{min}^{-1}$, respectively) and in control and macrosomic females (1.98 \pm 0.19 versus $2.21 \pm 0.22 \mathrm{mg} \cdot \mathrm{kg}^{-1} \mathrm{~min}^{-1}$, respectively)

\section{DISCUSSION}

The aim of this study was to investigate the mechanism of glucose intolerance among obese offspring of mildly hyperglycemic mothers. We used STZ treatment of pregnant rats to induce maternal hyperglycemia, resulting in obese, hyperinsulinemic offspring (4). Consistent with our previous work, these animals maintained an accelerated weight gain through $10 \mathrm{wk}$ of age, and oral glucose tolerance tests performed at $10 \mathrm{wk} \mathrm{dem-}$ onstrated that the experimental animals had abnormally elevated glucose and insulin levels compared to controls $(8,9)$. To further assess the mechanism of these responses in vivo, euglycemichyperinsulinemic clamp studies were performed. Clamp techniques have been proven to be useful in quantifying in vivo insulin sensitivity in humans (10-13). Miniaturization of these techniques now makes it possible to study in vivo sensitivity to hyperinsulinemia in the intact conscious rat (14-16). One advantage of the euglycemic clamp technique over the commonly used insulin tolerance test is that by maintaining euglycemia under hyperinsulinemic conditions, hypoglycemic reactions are avoided and a reliable estimate of tissue sensitivity to insulin can be made. The degree of hyperinsulinemia induced in all four groups was the same (433 to $511 \mathrm{pmol} / \mathrm{L})$. The amount of exogenous glucose required to maintain euglycemia during the hyperinsulinemic period of the clamp was significantly lower ( $p$ $<0.05)$ in the male and female macrosomic groups when compared to control males and females, respectively (Figure 5). Table 1 shows that for the last $60 \mathrm{~min}$ of the clamp, the experimental animals required an average $37 \%$ less glucose infused. Because steady state plasma insulin levels were comparable between the groups, the lower glucose infusion rate required to maintain euglycemia suggests that the obese animals were less sensitive to the increase in plasma insulin concentration than were the controls. One should not use the rate of glucose infused to maintain euglycemia during a hyperinsulinemic period as a measure of the effect of insulin on glucose disposal if glucose production is also being decreased at the same time. Therefore, 
Table 1. Body weight, blood glucose, plasma insulin, and increment in Rd per unit increase in insulin in study animals*

\begin{tabular}{|c|c|c|c|c|c|c|c|}
\hline \multirow[b]{2}{*}{ Group } & \multirow[b]{2}{*}{$n$} & \multirow[b]{2}{*}{ Body wt (g) } & \multicolumn{2}{|c|}{$\begin{array}{l}\text { Blood glucose } \\
(\mathrm{mmol} / \mathrm{L})\end{array}$} & \multicolumn{2}{|c|}{$\begin{array}{l}\text { Plasma insulin } \\
(\mathrm{pmol} / \mathrm{L})\end{array}$} & \multirow{2}{*}{$\begin{array}{c}\text { Increment in } \mathrm{Rd} \\
\left(\mathrm{mg} \cdot \mathrm{kg}^{-1} \cdot \mathrm{min}^{-1} \text { per } \mu \mathrm{U} / \mathrm{mL}\right)\end{array}$} \\
\hline & & & Basal & Steady state & Basal & Steady state & \\
\hline \multicolumn{8}{|l|}{ Male } \\
\hline Control & 9 & $373.90 \pm 15.70$ & $3.99 \pm 0.67$ & $4.66 \pm 1.17$ & $149 \pm 36$ & $433 \pm 43 \dagger$ & $0.11 \pm 0.02$ \\
\hline Macrosomic & 8 & $408.40 \pm 21.20 \ddagger$ & $4.44 \pm 0.94$ & $5.33 \pm 0.83$ & $178 \pm 71$ & $511 \pm 64 \dagger$ & $0.04 \pm 0.01 \ddagger$ \\
\hline \multicolumn{8}{|l|}{ Female } \\
\hline Control & 10 & $250.10 \pm 9.70$ & $4.22 \pm 0.67$ & $5.06 \pm 0.78$ & $170 \pm 36$ & $433 \pm 43 \dagger$ & $0.18 \pm 0.03$ \\
\hline Macrosomic & 10 & $266.10 \pm 17.70 \ddagger$ & $4.05 \pm 1.00$ & $5.27 \pm 1.05$ & $156 \pm 50$ & $469 \pm 36 \dagger$ & $0.05 \pm 0.01 \ddagger$ \\
\hline
\end{tabular}

$*$ Values are mean $\pm \mathrm{SD}$. Rd, glucose disposal rate.

$+p<0.05$ vs basal.

$\ddagger p<0.05$ vs control.

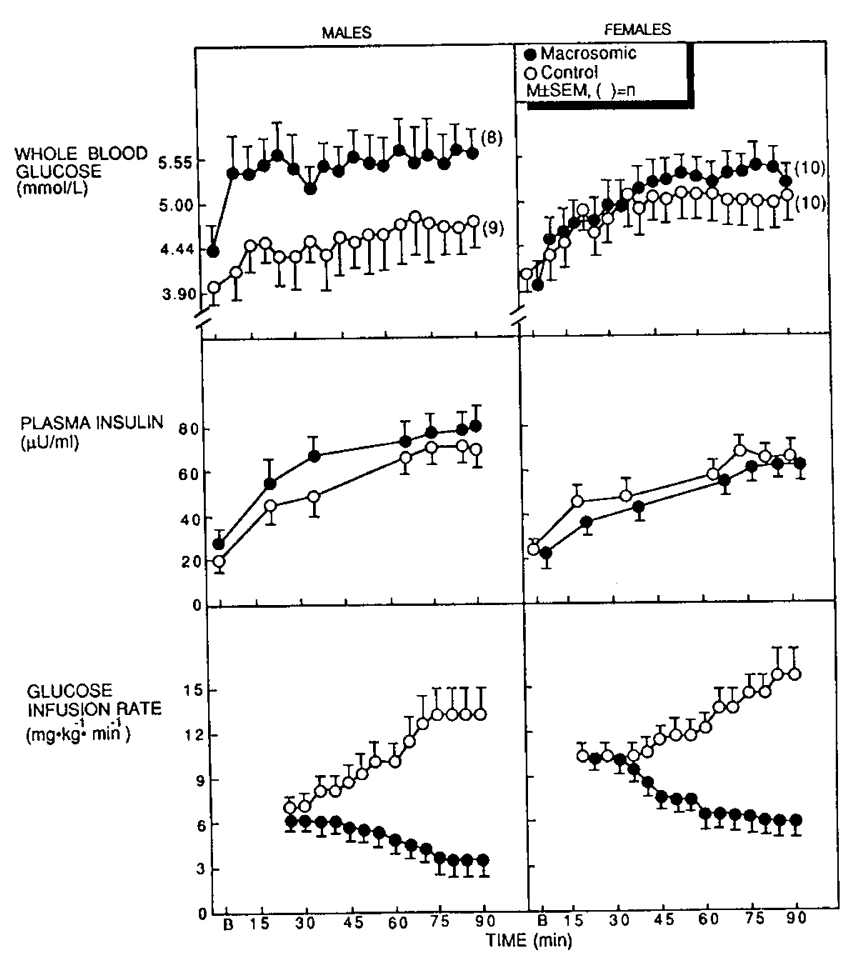

Fig. 5. Whole blood glucose, plasma insulin, and glucose infusion rates for males and females during the hyperinsulinemic-euglycemic clamp.

Table 2. Endogenous glucose production rate $\left(\mathrm{mg} \cdot \mathrm{kg}^{-1} \cdot \mathrm{min}^{-1}\right)^{*}$

\begin{tabular}{cccccc}
\hline Group & $n$ & Basal & Steady state & $p$ & Net suppression $\dagger$ \\
\hline Male & & & & & \\
Control & 9 & $2.48 \pm 0.26$ & $0.22 \pm 0.04$ & 0.05 & $2.23 \pm 0.21$ \\
Macro- & 8 & $3.48 \pm 0.20$ & $1.31 \pm 0.10$ & 0.05 & $2.32 \pm 0.35$ \\
$\quad$ somic & & & & & \\
$p$ & & 0.004 & 0.05 & & $\mathrm{NS}$ \\
$\begin{array}{c}\text { Female } \\
\text { Control }\end{array}$ & 10 & $2.43 \pm 0.33$ & $0.40 \pm 0.07$ & 0.05 & $1.98 \pm 0.19$ \\
$\begin{array}{c}\text { Macro- } \\
\quad\end{array}$ & 10 & $3.40 \pm 0.16$ & $1.24 \pm 0.78$ & 0.05 & $2.21 \pm 0.22$ \\
$\quad$ somic & & 0.01 & 0.05 & & $\mathrm{NS}$ \\
\hline
\end{tabular}

$*$ Values are mean \pm SEM.

$\uparrow$ Calculated as basal minus steady state values at similar plasma insulin concentrations.

to measure the insulin effect on glucose disposal, the insulin sensitivity index (17) (the increment in glucose disposal divided by the increment in insulin concentration) was calculated. The data show that, per unit insulin concentration, glucose disposal in the macrosomic males was significantly lower than in the control males $(p<0.01)$. A similar pattern was seen in the females, where macrosomic animals showed lower glucose disposal than controls $(p<0.001)$.

In euglycemic-hyperinsulinemic clamp studies, the assumption that exogenous glucose infused is a measure of total glucose metabolism presupposes that basal endogenous glucose production is suppressed by the infusion of glucose and insulin. If the production rate is not lower, however, this assumption may not be reliable (18). It is therefore essential that these studies be done in conjunction with tracer isotope to follow endogenous glucose production. ${ }^{14} \mathrm{C}$-glucose dilution technique provided the means to estimate endogenous glucose production. Calculating insulin suppression of glucose production on an absolute per $\mathrm{kg}$ basis, we found that endogenous glucose production was suppressed to the same degree in the macrosomic and control animals. These data suggest that insulin's effect at the hepatic level was comparable between the two groups and, therefore, hepatic insulin resistance during hyperinsulinemia was not in evidence. On the other hand, the suppressed endogenous glucose production rates in both male and female macrosomic rats during the basal state clearly suggest insulin resistance at the hepatic level; the equal degree of suppression of endogenous glucose production rates in these rats during the euglycemic-hyperinsulinemic period suggests that the hepatic insulin resistance in the basal state can be overcome by a high insulin level.

It is of interest that the hepatic resistance during the basal state is not associated with a high plasma insulin level. One possible explanation is that pancreatic islet cell function may have been compromised because of prenatal STZ exposure; however, in a previous work (8), we have shown that the fetuses from dams treated with STZ on the 5th day of gestation are hyperinsulinemic and have increased c-peptide levels compared to control dams fetuses. It would seem unlikely, therefore, that there is a deleterious effect of STZ of the fetal $\beta$-cells. Further investigation using isolated islet cells from control and macrosomic rats might shed some additional light on the status of insulin secretory capacity in these animals.

Five clamp experiments resulted in negative values for endogenous production: the values were $-0.38,-0.52,-0.56,-0.78$, and $-0.95 \mathrm{mg} \cdot \mathrm{kg}^{-1} \cdot \mathrm{min}^{-1}$. The tracer-dilution technique has been reported to underestimate glucose disposal during hyperinsulinemic-euglycemic clamp studies (19-21), resulting in physiologically impossible negative hepatic glucose production rates. The cause of this underestimation has been attributed to differences in metabolism of glucose tracer compared to unlabeled glucose and modeling errors for glucose kinetics. Argoud et al. (22) used both radioactive and stable isotopes that utilize different methodologies to determine whether discriminant isotope metabolism or possible methodologic error results in underestimated glucose disposal rates. They concluded that because both stable and radioactive isotopes resulted in negative disposal rates, differential metabolism of tracers is a probable cause for glucose disposal rates that are discrepant from those determined using unlabeled glucose. Finegood et al. (23) has suggested that, in addition to discriminant tracer metabolism, insufficient model- 
ing may also confound interpretation of estimates of endogenous glucose production. They suggest that a one-compartment model with a variable volume be used to correct the maximum possible $20 \%$ error in the underestimate of true glucose disposal due to insufficient modeling. These possible sources of error may be the cause of the negative values obtained in the studies listed above.

In summary, the obese offspring of mildly hyperglycemic dams maintain an accelerated weight gain and develop glucose intolerance by $10 \mathrm{wk}$ of age. The euglycemic-hyperinsulinemic clamp studies provide in vivo evidence to suggest basal (fasted) state hepatic insulin resistance as well as peripheral tissue insulin resistance as probable causes of glucose intolerance in these obese animals.

\section{REFERENCES}

1. Vohr BR, Lipsitt LP, Oh W 1980 Somatic growth of children of diabetic mothers with reference to birth size. J Pediatr 97:196-199

2. Pettit DJ, Baird HR, Aleck KH, Bennett PH, Knowler WC 1983 Excessive obesity in offspring of Pima Indian women with diabetes during pregnancy. N Engl J Med 308:242-245

3. Lebovitz HE 1984 Etiology and pathogenesis of diabetes mellitus. Pediatr Clin North Am 31:521-530

4. Oh W, Gelardi NL, Cha C-J 1988 Mild maternal hyperglycemia during pregnancy: its effect on growth and insulin metabolism in the offspring. Metabolism 37:1146-1151

5. Gelardi NL, Cha C-J, Oh W 1990 Glucose metabolism in adipocytes of obese offspring of mild hyperglycemic rats. Pediatr Res 28:641-645

6. Kraegen EW, James DE, Bennett SP, Chisholm DJ 1983 In vivo insulin sensitivity in the rat determined by euglycemic clamp. Am J Physiol 245:E1E7

7. Steele R, Wall JE, DeBodo RC, Altszuler N 1956 Measurement of size and turnover rate of body glucose pool by the iosotope dilution method. Am J Physiol 187:15-24

8. Catlin EA, Cha C-JM, Oh W 1985 Postnatal growth and fatty acid synthesis in insulin-induced macrosomic rat pups. Metabolism 34:1110-1114
9. Cha C-JM, Gelardi NL, Oh W 1987 Accelerated growth and abnormal glucose tolerance in young female rats exposed to fetal hyperinsulinemia. Pediatr Res 21:83-87

10. DeFronzo R, Tobin JD, Andres R 1979 Glucose clamp technique; a method for quantifying insulin secretion and resistance. Am J Physiol 237:E214E215

11. DeFronzo R, Ferrannini E, Hendler R, Wahren S, Felig P 1978 Influence of hyperinsulinemia, hyperglycemia, and the route of glucose administration on splanchnic glucose exchange. Proc Natl Acad Sci USA 75:5173-5177

12. Rizza RA, Mandarino LJ, Gerich JE 1981 Dose-response characteristics for effects of insulin on production and utilization of glucose in man. Am J Physiol 240:E630-E639

13. DeFronzo RA 1979 Glucose intolerance and aging. Evidence for tissue insensitivity to insulin. Diabetes 28:1095-1101

14. Leturque A, Burnol AF, Ferre P, Girard J 1984 Pregnancy-induced insulin resistance in the rat: assessment by glucose clamp technique. Am J Physiol
246:E25-E31

15. Terrettaz J, Jeanrenaud B 1983 In vivo hepatic and peripheral insulin resistance in genetically obese (fa/fa) rats. Endocrinology 112:1346-1351

16. Smith D, Rossetti L, Ferrannini E, Johnson CM, Cobelli C, Toffolo G, Katz LD, DeFronzo RA 1987 In vivo glucose metabolism in the awake rat: trace and insulin clamp studies. Metabolism 36:1167-1174

17. Bergman RN, Finegood DT, Ader M 1985 Assessment of insulin sensitivity in vivo. Endocr Rev 6:45-86

18. DeFronzo RA, Soman V, Sherwin RS, Hendler R, Felig P 1978 Insulin binding to monocytes and insulin action in human obesity, starvation, and refeeding.
$\mathrm{J}$ Clin Invest $62: 204-213$

19. Finegood DT, Vranic M 1985 Possible isotope effect of tritiated glucose tracer during hyperinsulinemic, euglycemic glucose clamps. Diabetes 36:80A(abstr)

20. Bell PM, Firth RG, Rizza RA 1986 Assessment of insulin action in insulin dependent diabetes mellitus using $6-{ }^{14} \mathrm{C}$ glucose, $3-{ }^{3} \mathrm{H}$ glucose and $2-{ }^{3} \mathrm{H}$ glucose. J Clin Invest 78:1479-1486

21. Verdin E, Castillo M, Luyckx AS, Lefebvre PJ 1984 Similar metabolic effects of pulsatile versus continuous human insulin delivery during euglycemic hyperinsulinemic glucose clamp on normal man. Diabetes 33:1 169-1174

22. Argoud GM, Schade DS, Eaton RP 1987 Underestimation of hepatic glucose production by radioactive and stable tracers. Am J Physiol 252:E606-E615

23. Finegood DT, Bergman RN, Vranic M 1988 Modeling error and apparen isotope discrimination confound estimation of endogenous glucose production during euglycemic glucose clamps. Diabetes 37:1025-1034 